\title{
Risk and Crisis Communication in Colombia: a Case Study from Medellín
}

\author{
Michael Klafft \\ Jade University of Applied Sciences and Fraunhofer FOKUS \\ Friedrich-Paffrath-Str. 101, 26389 Wilhelmshaven, Germany \\ Pia Schreiber \\ Jade University of Applied Sciences \\ Friedrich-Paffrath-Str. 101, 26389 Wilhelmshaven, Germany
}

\begin{abstract}
This paper analyses the state of the art of risk and crisis communication in Colombia with a focus on natural and man-made risks and disasters. Findings are based on a series of semi-structured interviews with risk and crisis communication experts, practitioners, and educational experts from the city of Medellín, and on a content analysis of teaching materials used for risk communication. The study reveals that a combination of different approaches is used to raise risk awareness in the population, combining education through entertainment, citizen sciences projects, and risk communication via the website and app of a regional alerting system.
\end{abstract}

Keywords - Risk and Crisis Communication, Colombia, Education through Entertainment, Citizen Science, Alerting Systems.

SUGGESTED CITATION: Klafft, M., \& Schreiber, P. (2018). Risk and crisis communication in Colombia: A case study from Medellín. Proceedings of the International Crisis and Risk Communication Conference (pp. 8-11). Orlando, FL, USA. Nicholson School of Communication. https://doi.org/10.30658/icrcc.2018.3

\section{INTRODUCTION}

Until recently, only limited research on risk and crisis communication has been undertaken in Colombia [1], and scientific discussions have mostly been related to armed conflict and the drug-trafficking crisis [1], because those two issues had an important impact on the country's society in the past. Some studies on the coverage of natural disasters by the media exist, and they show that media tend to dramatize natural disasters if they happen [2], and that media rather focus on personal tragedies related to such disasters instead of focusing on the causes of and responsibilities for the disasters [3]. In order to complement these existing studies, we decided to use a different approach and to analyse the experiences and strategies applied by risk communication practitioners to raise risk awareness and to increase resilience in the population. This included an analysis of the work of official risk communicators employed by the state, risk communicators from NGOs, and risk communication within the educational system. The remainder of the paper is structured as follows: the next section describes the setting of the case study, followed by a section on the methods used to generate data for analysis. Thereafter, key findings are presented. After a discussion of these findings, an outlook outlines the next steps which are currently being undertaken by the Colombian government to further improve risk and crisis communication in the country.

\section{THE CASE OF MEDELLÍN}

Medellin metropolitan with its 3.7 million inhabitants is the second largest metropolitan area in Colombia, and is situated in the Aburra valley. The area is characterized by high social inequality [4]. Continuous population growth led to an (often unplanned) extension of settlements into zones with steep mountain slopes, where the risk of natural disasters is high (in particular caused by heavy rain leading to inundations, mudslides and scourings). The existing canalization is often operating close to max-capacity under normal conditions, and is not capable of handling additional inflows caused by heavy rain. The high-risk settlements at the mountain slopes are mainly inhabited by economically weak population groups (high share of strata 1 and 2 of the Colombian classification system). However, government, administration, and NGOs have undertaken substantial efforts to improve conditions in the quarters concerned. This includes investments 
into improved risk and crisis communication. The Aburra valley operates Colombia's most advanced early warning system SIATA ("Sístema de Alerta Temprana de Medellín y el Valle de Aburrá”). The city also hosts a large exhibition / park for science communication ("Parque Explora") and several institutions of Higher Education, one of which organizes an internationally renowned children's university (Universidad de niños EAFIT), which addresses pupils from the whole spectrum of society.

\section{METHOD}

In order to gain a deeper understanding how risk communication practitioners in Medellín deal with communication on natural and man-made risks, semi-structured interviews were conducted with the following participants:

1. Two representatives of the regional early warning system SIATA

2. Three representatives of the regional section of the Colombian Red Cross, interviewees were responsible for communication (with citizens and volunteers), and educational activities.

3. Several communicators, lecturers, conceptual designers, and assistants from EAFIT children's university

Interviews were in part conducted as individual interviews and in part as group interviews, depending on the availability of the interviewees. In addition to the input from the interviews, the content and approach of educational materials from the Colombian Red Cross [5][6][7] were analysed, and the website [8] and app of the alerting system were reviewed.

\section{RESULTS}

Interviews indicate that both governmental stakeholders like the early warning system SIATA and non-governmental organizations like the Colombian Red Cross undertake considerable efforts to inform the population about existing risks related to natural disasters. In doing so, a combination of different approaches is used:

1. Providing up to date information to the public. Via its website [8] and app, the alerting system SIATA provides very detailed information on many environmental aspects to the public. This includes, among others, weather radar data, data from different types of weather sensors (e.g. precipitation), water level sensors in rivers, and data from air pollution sensors. In order to make interpretation of these data easier for the general public, icons and color-based schemes are used to indicate if any of the data is "off-normal" and represents a risk for the public. Experts who want to have a more detailed view on the data are also able to click on the different icons to execute a drill down and to obtain more information on sensor type, location, as well as visualized time series of the sensor data. SIATA also provide access to different webcams located throughout the city, so that citizens and experts alike can watch the video stream in order to carry out a visual verification of, for example, upcoming or ongoing weather phenomena. In addition to these near-real-time data, the alerting system's website also provides risk maps which indicate areas in the city with an elevated risk of flooding or mass movements. While the website provides very detailed information and is therefore more suitable for experts, the related app provides some key information in an easily accessible way and is therefore also easy to use for citizens. By including the actual weather forecast in the app, SIATA has created an incentive to use the app on an everyday basis outside a risk / disaster context, which is helpful in gaining a considerable user base.

2. Education through entertainment approaches. The Colombian Red Cross has created a series of playful educational materials based upon an animated movie called the "Chickenology of Disasters" [6], which tells the tale of chickenland whose inhabitants are threatened by a cat from neighbouring catland. This cat repeatedly "visits" the chicken and causes havoc and destruction. This tale is used to explain several key concepts of disaster prevention and management: emergency planning, monitoring, early warning and alerting, disaster preparedness, and concepts like risk levels and vulnerability. In order to make the key issues more memorisable, the "PR3EMIA" strategy is presented, based upon the concepts of PREvision, PREvention, PREparation, MItigation, and Alerting. In addition to the animated movie, the Colombian Red Cross also edited a book [5] where these concepts are explained in more detail, and which includes several games for the children which help them to learn in a playful way, such as: assigning disaster types to different icons, detecting hidden phrases related to disaster management in a rectangle full of seemingly random letters, evacuating through a labyrinth, or solving a crossword puzzle on risks. In addition to these more general materials, the regional direction of the Colombian Red Cross also created an animated movie on inundation risks [7]. In this video two (fictitious) children learn at school about the inundation risk and protective measures, discuss what they have learnt at home with their parents, and thus help the family to evacuate successfully when disaster comes. As can be seen from the abovementioned examples, the education through entertainment approach is targeting children with the goal to use them as multipliers within society.

3. Citizen science projects. At the time of our study (September 2017), the early warning system SIATA was working with citizens in a project called "Ciudadanos Cientificos” which had the goal to collect more detailed 
information about air pollution in the city. SIATA assembled and distributed low-cost sensor platforms which are capable of measuring different air parameters (such as the presence of particulate matter in the air). Citizens cooperate in this project by mounting the sensor platforms outside their homes. A separate app [9] allows citizens and experts alike to see the data of the different sensors. Besides collecting data on air quality, this project has the (intended) side effect that citizens who "host" a sensor outside their home present it to their family, friends, and neighbours, thus starting a discussion on the issue of air quality within the different communities. This makes people more aware of the problem of air pollution and related health risks.

In addition to the abovementioned approaches used by key stakeholders for risk communication in the region of Medellín, some educational institutions also (indirectly) support the risk communication efforts. At EAFIT children's university, for example, phenomena leading to different types of natural and man-made risks are discussed as part of their curriculum. One example is a module on the question "Why do rivers overflow?", where natural and man-made causes for flooding were examined, such as deforestation, or the blocking of river flows by debris [10]. Although the primary purpose of these modules rather is education than risk communication, these courses do provide a deeper understanding of underlying problems and therefore contribute to a better risk awareness in the population.

\section{DISCUSSION}

Our study shows that considerable efforts are undertaken by governmental actors as well as not-for-profit organizations in the Medellín area to inform the population about relevant natural and man- made risks in their area. While doing so, the stakeholders are trying to maximize the impact of their efforts through multiplier effects, such as by communicating risks to children and motivate them to discuss these risks with their parents and families, or by involving citizens in data collection projects in order to stimulate discussions within threatened communities. The existing alerting system - which rather acts as an information system, because it does not include a dedicated alerting functionality - provides very detailed information from many different sources. It therefore enables experts to gain a good situational picture, while the app - with somewhat reduced functionality - is well suited to inform the citizens about some key risks such as inundations. It can therefore be said that - at least in the Medellín area - risk communication is now focusing clearly towards risk awareness, prevention, early warning, and preparation, contrary to previous findings in [1], which pointed out that in most cases analysed so far, the focus of risk and crisis communication by authorities was more on reaction than on preparedness.

\section{OUTLOOK}

In the wake of the Mocoa disaster, which occurred in 2017 and in which more than 300 people were killed by inundations and mudslides, Colombian authorities have further intensified their efforts to improve risk and crisis communication infrastructures throughout the country. It is, for example, currently planned to expand the coverage of alerting systems beyond the Medellín area. In order to guarantee the optimal impact of these systems, alerting the population at risk has to be assured. This requires a combination of different communication channels and media, some of which have to provide a strong wake-up effect to draw the attention of the people to the fact that an alert has been issued. One way to support this goal could be the inclusion of an alerting functionality with a dedicated alert sound in SIATA's app.

\section{Author Biography}

Michael Klafft is Professor for Information Systems and Digital Media at Jade University of Applied Sciences. He holds a PhD in Information Systems from Humboldt University, Berlin. E-Mail: Michael.Klafft@jade-hs.de.

Pia Schreiber is Lecturer at Jade University of Applied Sciences. She holds a PhD from University of Münster. E-Mail: Pia.Schreiber@jade-hs.de.

\section{REFERENCES}

[1] Arroyave, J., Erazo-Coronado, A.M. (2016). Crisis and Risk Communication Research in Colombia. In A. Schwarz, M.W. Seeger, C. Auer (Eds.), The Handbook of International Crisis Communication Research (pp. 411-421). Chichester, UK: Wiley

[2] Hermelín, D. (2007). Los desastres naturales y los medios en Colombia: ¿Información para la prevención? Revista Gestión y Ambiente, 10(2), 101-108

[3] Obregón, R., Arroyave, J., Barrios, M. (2010). Periodismo y comunicación para la gestión de riesgo en la subregión Andina: discursos periodísticos y perspectivas para un enfoque prospectivo y preventivo. Revista folios, 23, 105-135

[4] Brand, P. (2013). Governing inequality in the South through the Barcelona model: social urbanism in Medellín, Colombia. In Proceedings Interrogating Urban Crisis: Governance, Contestation, Critique, 17 pp. 
[5] Cotte, W. R. (2007). Libro de Juegos Pollologia de los Desastres. Bogota, Colombia: Sociedad Nacional de la Cruz Roja Colombiana

[6] Cruz Roja de Colombia (2011). Pollolandia Prevenida. https://www.youtube.com/watch?v=GyEekOaSeLc\&t=38s

[7] Cruz Roja Colombiana Seccional Antioquia (2014). Video educativo de gestión del riesgo por inundación. https://www.youtube.com/watch?v=oOoE7tLuvEE

[8] SIATA (2018). Sístema de Alerta Temprana del Valle de Aburrá. https://siata.gov.co/siata_nuevo/

[9] SIATA (2018). Ciudadanos Cientificos https://play.google.com/store/apps/details?id=co.gov.siata.ciudadano_cientifico\&hl=es_419

[10] Restrepo Restrepo, S. (2016). ¿Por Qué Desbordan los Rios?, Catalejo 9, 10-11 